die Seiten hinten deutlich abgesetzt, in der Mitte einen stumpf abgerundeten Winkel bildend, der Hinterrand von vorn gesehen, vor dem Schildchen eine stumpf dreieckige Spitze bildend, die Hinterecken fast abgerundet, die Oberfläche dicht mit längeren, abstehenden gelbbraunen Haaren bedeckt, ohne Spiegelfleck vor der Mitte; auf der Mittellinie und an den Seiten, namentlich hinten sind kürzere, stärkere greise Härchen eingemischt, die das Hlsch. an den betreffenden Stellen grauweifs erscheinen lassen. Der Hinterrand des Hlsch. ist mit längeren, gelblichen Haarzotten besetzt. Das Scutellum ist sehr dicht und fein weifslich-grau behaart. Die Fld. sind dicht mit kurzen, graulichen Härchen besetzt; neben dem Seitenrande läuft vorn eine deutliche Rippe, die unter der Schulter beginnt und hinter der Mitte verschwindet, zwei andere Rippen sind kaum angedeutet. Pygidium und Hinterleib sind bräunlich, äufserst fein pubescent. Vorder-, Mittel- und Hinterbrust sind dicht und lang, zottig gelb behaart. Die Beine sind wenig kräftig, die Tarsen schlanker als bei paupera, die vorderen an der inneren Klaue, die mittleren und hinteren an der äufseren Klave mit einem längeren Zähnchen versehen, die Vorderschienen mit drei scharfen Zähnen, die mittleren deutlich zweizähnig, die hinteren ebenfalls, der obere Zahn aber kaum sichtbar. Die Schenkel sind unten lang zottig, die Schienen innen lang fein behaart.

\title{
Theodosia Westwoodi Kraatz n. sp.
}

Von Herrn Dr. Staudinger erhielt ich zugleich mit Theodosia telifer Bates eine Art, welche in der Mitte zwischen ihr und Theodosia (Westwoodia Guérin), Howittii Casteln. zu stehen scheint; sie ist merklich grölser als telifer und hat ein Kopfhorn, welches viel länger, an der Spitze nicht gespalten ist und etwas über das Thoracalhorn hinausreicht. Andererseits ist die neue Art kleiner als Howittii Cast. (welche 40 mill. lang ist), die Vorderecken des Clypeus sind weniger lang ausgezogen, das Kopfhorn ist etwas kürzer, das Thoracalhorn zeigt etwa eine Linie vor der Spitze unten jederseits einen kleinen Höcker und wiederum eine Linie vor diesem Seitenhöcker unten einige Tuberkeln. Die Flügeldecken der Howittii scheinen etwas dunkler zu sein, denn Castelnau nennt sie „un peu métallico-testacés", während sie beim Westwoodi gelblich (flavescentes) wie beim telifer sind. 
Die Diagnose der Westwoodi, von dem mir nur ein $\sigma^{\star}$ vorliegt, würde etwa so láuten:

Theodosia Westwoodi: Elongato-oblonga, aurescenti-viridis, elytris planatis flavescentibus. $\sigma^{T}$ capite et thorace densissime confluenter punctulatis, subopacis, hoc dorso nitidulo, saturatius viridi, scutello viridi, elytris densissime punctulatis, flavescentibus; capitis cornu id thoracis paullulum superante, acuminato, purpurascenti thoracis cornu apice subtruncato paullo ante apicem utrinque tuberculato-dilatato subtusque tuberculis nonnullis praedito; abdomine viridi-flavescenti. - Long. 34 mill.

Mit Ausnahme des Kopfhornes, welches purpurroth (nicht grünlich) und zugespitzt ist und der hornartigen Verlängerung des Halsschildes, welche vor der abgestutzten Spitze jederseits tuberkelartig erweitert ist, dem telifer sehr ähnlich, die Fld. ohne jede Spur von Punkten. Der grüne Glanz der Scheibe des Halsschildes ist etwas lebhafter, ebenso der Purpurglanz des Hornes. Das Schildchen ist ganz ähnlich sculptirt, wie das Halsschild grünlich. Die Fld. sind gelblich, noch weniger bräunlich angehaucht als beim telifer.

Theod. Howittii ist grölser, das Horn des Halsschildes w eniger lang, unten und an den Seiten ganz eben.

Mit telifer zugleich vom Kinibalu-Gebirge aus Borneo von Dr. Staudinger eingesendet.

Thomson hat bekanntlich die Gattung Westwoodia in Theodosia umgetauft (Annal. Soc. France 1880, p. CI) und dabei gleichzeitig die Gattung Helionica ( $p$. CII) aus dem nördlichen Borneo aufgestellt, deren Clypeus vorn nicht in saillies coniformes verlängert und in der Mitte mit einem kürzeren, robusteren Horn versehen ist, deren Thoraxhorn unten gekielt sein soll. Ich habe Helionica Westwoodii nie zu Gesicht bekommen, halte sie indessen kaum für generisch von Theodosia verschieden.

Theodosia Westwoodi kann nicht wohl identisch mit Helionica sein, weil ihr Thoracalhorn vor der Spitze jederseits einen Höcker hat und auch unten mit Höckerchen versehen ist; die Grölse ist ungefähr dieselbe.

Dr. G. Kraatz. 


\section{$2 \mathrm{BHL}$ Biodiversity Heritage Library}

Kraatz, G. 1894. "Theodosia Westwoodi Kraatz n. sp." Deutsche entomologische Zeitschrift 1894(5), 291-292. https://doi.org/10.1002/mmnd.48018940534.

View This Item Online: https://www.biodiversitylibrary.org/item/103425

DOI: https://doi.org/10.1002/mmnd.48018940534

Permalink: https://www.biodiversitylibrary.org/partpdf/235573

\section{Holding Institution}

Harvard University, Museum of Comparative Zoology, Ernst Mayr Library

\section{Sponsored by}

Harvard University, Museum of Comparative Zoology, Ernst Mayr Library

\section{Copyright \& Reuse}

Copyright Status: Public domain. The BHL considers that this work is no longer under copyright protection.

This document was created from content at the Biodiversity Heritage Library, the world's largest open access digital library for biodiversity literature and archives. Visit BHL at https://www.biodiversitylibrary.org. 